\title{
Voltage-Mode Universal Biquadratic Filters Using OTA-URC
}

\author{
S. Klungtong, V. Pirajnanchai, P. Rakluea, and K. Janchitrapongvej
}

\begin{abstract}
This paper present new universal biquad filter employing OTA and URC (Uniform Distributed RC). The features of the proposed circuit are that: the circuit topologies are very simple consisting of 2 OTA and $2 U R C$, where either one of the three filtering transfer function (LPF, HPF, BPF and BRF) can be achieved by this only one filter. In addition, higher filtering response frequency $\left(\omega_{P}\right)$ can be obtained through adjusting bias current of OTAs without affecting its quality factor $\left(Q_{P}\right)$ stability. Characteristics of the proposed filter are simulated using PSpice and its results are in agreement with the theory.
\end{abstract}

Index Terms-Universal biquad, OTA, uniform distributed $\mathrm{RC}$, response frequency $\left(\omega_{P}\right)$, quality factor $\left(Q_{P}\right)$.

\section{INTRODUCTION}

Many current and voltage mode universal Biquadratic filter circuits employing operational transconductance amplifier (OTA) had been reported in the literature [1]-[7]. These designs of OTA-C filter circuit require no resistors. Therefore, they are suitable for monolithic integration than the other current conveyors. Moreover an OTA provides a highly linear electronic and a wide tunable range of the transconductance gain. Therefore, the filters based on OTAs are the attention for many researches. The characteristics of Uniform Distributed RC (URC) element have several advantages over lumped RC network. The structure of distributed RC elements in thin-film technology is built using smaller high frequency. Distributed RC elements may have many form structure. For instance, one capacitive layer, double capacitive layers and multi layer thin-film structure. The structure of the general URC consists of layers of conductors, resistive layer and dielectrics can be sandwiched together in many permutations. The resistive or conductive layers may be contacted at various points around their edges. Other advantages are applied to active filters. For instance single capacitive layer $U R C$ [8] in conjunction with amplifier in literatures respectively.

This paper introduces a voltage-mode universal biquad filter using two OTAs and two URC the filter can realize the low-pass (LPF), the high-pass (HPF), the band-pass (BPF) and band reject (BRF) transfer function by connecting the terminal $\mathrm{V}_{\mathrm{a}} \mathrm{V}_{\mathrm{b}}$ and $\mathrm{V}_{\mathrm{c}}$ to the ground or to the input voltage $\mathrm{V}_{\mathrm{g}}$.

Manuscript received June 18, 2012; revised July 20, 2012.

S. Klungtong, V. Pirajnanchai, P. Rakluea are with the Electrical Engineering Department, Rajamangala University of Technology Thanyaburi, Pathumthani, 12110, Thailand (e-mail: suapchaik@gmail.com).

K. Janchitrapongvej is with the Electrical Engineering Department, Faculty of Engineering, King Mongkut's Institute of Technology Ladkrabang, Bangkok, 10520, Thailand.
The characteristic parameters $\omega_{P}$ and $Q_{P}$ can also be set orthogonally by adjusting the bias currents of the OTA. Some examples are given together with simulated results by PSpice.

\section{CIRCUIT DESCRIPTION}

\section{A. Operational Transconductance Amplifier (OTA)}

An operational transconductance amplifier (OTA) is widely used as an active element in analog signal processing circuit. It is a differential input voltage controlled current source (DVVCS) device. The port relation of OTA as shown in Fig. 1(a) and equivalent circuit of the ideal OTA is shown in Fig. 1(b).

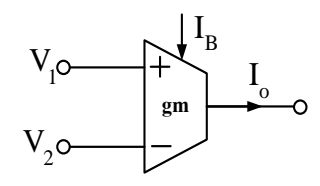

(a)

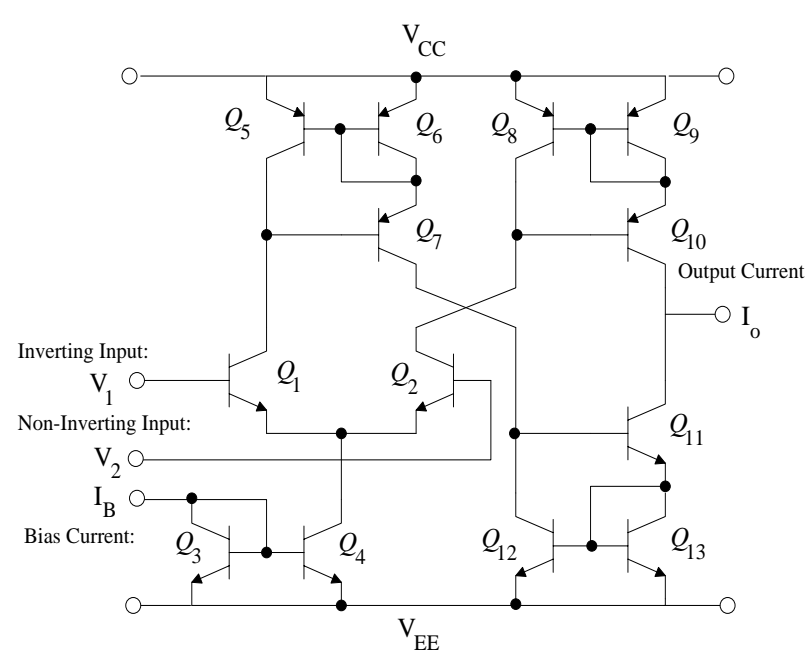

(c)

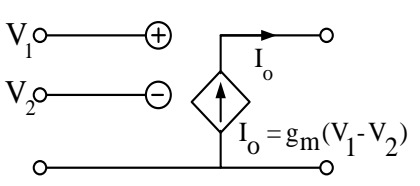

(b)
Fig. 1. (a) OTA symbol (b) Equivalent circuit and (c) Internal topology of OTA

The OTA element is given by the following equation:

$$
I_{O}=g_{m}\left(V_{1}-V_{2}\right)
$$

where, $\mathrm{V}_{1}, \mathrm{~V}_{2}$ is the differential input voltage, $I_{o}$ is the OTA output current and $\mathrm{g}_{\mathrm{m}}$ the transconductance gain is tunable through bias current $\mathrm{I}_{\mathrm{B}}$ is given by $\mathrm{g}_{\mathrm{m}}=\mathrm{I}_{\mathrm{B}} / 2 \mathrm{~V}_{\mathrm{T}}$ where, $V_{T}$ is the thermal voltage (26mv). [9]

\section{B. Uniform Distributed RC}

It is know that the uniformly Distributed RC element 
$(U R C)$ have several advantage over lumped RC network. The structure of distributed RC element in thin-film or LSI technology is built using smaller substrate area, less isolation and parasitic problem at high frequency, Distributed RC elements may have many form structure. [10] The structure and circuit symbol of uniformly distributed RC elements $(U R C)$ is illustrated in Fig.2

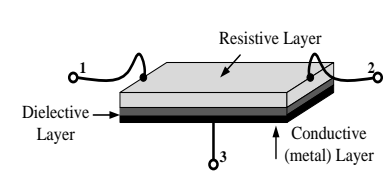

(a)

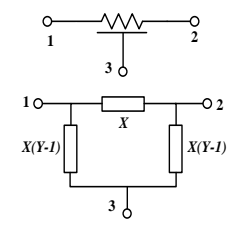

(b)
Fig. 2. a) A uniformly distributed RC section,

(b) Are symbolic and its equivalent lumped $\pi$ network

The admittance parameter [Yij] of the two port network $U R C$ in Fig. 2 is given as follows:

$$
\left[\begin{array}{l}
I_{1} \\
I_{2} \\
I_{3}
\end{array}\right]=X\left[\begin{array}{ccc}
Y & -1 & -(Y-1) \\
-1 & Y & -(Y-1) \\
-(Y-1) & -(Y-1) & 2(Y-1)
\end{array}\right]\left[\begin{array}{l}
V_{1} \\
V_{2} \\
V_{3}
\end{array}\right]
$$

when $X=\frac{P}{R \sinh P}, \quad Y=\cosh p \quad$ and $\quad P=\sqrt{s R C}$

where $\mathrm{R}$ and $\mathrm{C}$ are the value of the total resistance and capacitance of the capacitive $U R C$ respectively and $s$ is the complex frequency variable.

\section{OTA-URC PROPOSE CIRCUIT}

A simple universal OTA-URC Biquad realized with only four element is shown in Fig.3 This Biquad can be used a lowpass, highpass and bandreject second-order filter section. The required transfer function is realized by connecting the terminal $V_{a}, V_{b}$ and $V_{c}$ to the ground or to the input voltage $V_{g}$. The output voltage is $V_{o}$.

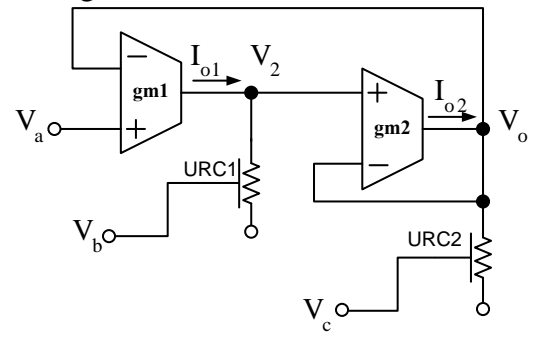

Fig. 3. OTA-URC circuit proposes universal biquad filter.

Fig. 3 shows a proposed OTA-URC circuit universal biquad filter. The transfer function of the circuit is given as follows:

$$
T(s)=\frac{V_{o}}{V_{g}}=\frac{\delta \frac{V_{a}}{V_{g}}-g_{m 2} R_{2} P_{1} \eta_{3} \sinh P_{2} \frac{V_{b}}{V_{g}}-P_{1} P_{2} \eta_{1} \eta_{4} \frac{V_{c}}{V_{g}}}{P_{1} P_{2} \eta_{1} \eta_{2}+g_{m 2} R_{2} P_{1} \eta_{1} \sinh P_{2}+\delta}
$$

Case low-pass is set $V_{a}=V_{g}, V_{b}=0$ and $V_{c}=0$. The transfer function $\mathrm{T}_{\mathrm{LP}}(\mathrm{s})$ of the circuit is given as follows:

$$
T_{L P}(s)=\frac{\delta}{P_{1} P_{2} \eta_{1} \eta_{2}+g_{m 2} R_{2} P_{1} \eta_{1} \sinh P_{2}+\delta}
$$

Case high-pass is set $V_{a}=0, V_{b}=0$ and $V_{c}=V_{g}$. The transfer function $\mathrm{T}_{\mathrm{HP}}(\mathrm{s})$ of the circuit is given as follows:

$$
T_{H P}(s)=\frac{-P_{1} P_{2} \eta_{1} \eta_{4}}{P_{1} P_{2} \eta_{1} \eta_{2}+g_{m 2} R_{2} \sinh P_{2}+\delta}
$$

Case band-pass is set $V_{a}=0, V_{b}=V_{g}$ and $V_{c}=0$. The transfer function $\mathrm{T}_{\mathrm{BP}}(\mathrm{s})$ of the circuit is given as follows:

$$
T_{B P}(s)=\frac{-g_{m 2} R_{2} P_{1} \eta_{3} \sinh P_{2}}{P_{1} P_{2} \eta_{1} \eta_{2}+g_{m 2} R_{2} P_{1} \sinh P_{2}+\delta}
$$

Case band-reject is set $V_{a}=V_{g}, V_{b}=0$ and $V_{c}=V_{g}$. The transfer function $\mathrm{T}_{\mathrm{RP}}(\mathrm{s})$ of the circuit is given as follows:

$$
T_{R P}(s)=\frac{\delta-P_{1} P_{2} \eta_{1} \eta_{4}}{P_{1} P_{2} \eta_{1} \eta_{2}+g_{m 2} R_{2} P_{1} \eta_{1} \sinh P_{2}-\delta}
$$

where

$$
\begin{aligned}
& \eta_{1}=\cosh P_{1}-1, \quad \eta_{2}=\cosh P_{2}-1, \quad \eta_{3}=2-\cosh P_{1}, \\
& \eta_{4}=2-\cosh P_{2}, \quad \delta=g_{m 1} g_{m 2} R_{1} R_{2} \sinh P_{1} \sinh P_{2} \\
& P_{1}=\sqrt{s R_{1} C_{1}}, \quad P_{1}=\sqrt{s R_{2} C_{2}}
\end{aligned}
$$

The pole magnitude $\left(\omega_{P}\right)$ and the pole $Q$-Factor $\left(Q_{P}\right)$ are given by

$$
\omega_{P}=\sqrt{\frac{g_{m 1} g_{m 2}}{C_{1} C_{2}}}, \quad Q_{P}=\sqrt{\frac{g_{m 1} C_{2}}{g_{m 2} C_{1}}}
$$

The $Q$-factor $\left(Q_{P}\right)$ is determined by the capacitance ratio, $\mathrm{C}_{2} / \mathrm{C}_{1}$, and the transconductance ratio, $\mathrm{g}_{\mathrm{m} 1} / \mathrm{g}_{\mathrm{m} 2}$. The most sensitive parameter, $\omega_{P}, \quad$ is a function of the transconductance-capacitance ratio, $\mathrm{g}_{\mathrm{m}} / \mathrm{C}$.

\section{Simulation Results}

To prove the performance of the propose circuit, a PSpice simulation was performed for examination. The PNP and NPN transistors employed in the proposed circuit were simulated by using the parameters of the PR200N and NR200N bipolar transistors of ALA400 transistor array from AT\&T [11] with the parameters summarized in Table I. The frequency response and phase response is shown in Fig.4 and Fig.5 are respectively. The $U R C$ is approximated by the ladder lumped RC elements of 10 sections, and the operational transconductance amplifiers using (OTA).

The simulation results for different filter responses Fig.4.The transconductance gain $g_{m s}$ of all OTAs were set $\mathrm{VCC} \pm 12 \mathrm{~V}, I_{B I}=I_{B 2}=100 \mu \mathrm{A}$. We selected the $U R C$ element value $\mathrm{R} 1=100 \Omega, \mathrm{R} 2=2 \mathrm{M} \Omega, \mathrm{C} 1=10 \mathrm{nF}$ and $\mathrm{C} 2=300 \mathrm{nF}$ to obtain low-pass, high-pass, band-pass and band-reject in Fig. 3 at frequency response $25.878 \mathrm{kHz}$. The simulated and experimental results are in good agreement with each other. 
TABLE I INDIVIDUAL PARAMETERS OF THE TRANSISTORS MODEL PX2 PNP RB $=163.5 \mathrm{IRB}=0 \mathrm{RBM}=12.27$ $\mathrm{RC}=25+\mathrm{RE}=1.5 \mathrm{IS}=147 \mathrm{E}-18 \mathrm{EG}=1.206 \mathrm{XTI}=1.7$ $\mathrm{XTB}=1.866+\mathrm{BF}=110 \mathrm{IKF}=4.718 \mathrm{E}-3 \mathrm{NF}=1 \mathrm{VAF}=51.8$ $\mathrm{ISE}=50.2 \mathrm{E}-16+\mathrm{NE}=1.650 \mathrm{BR}=0.4745 \mathrm{IKR}=12.96 \mathrm{E}-3$ $\mathrm{NR}=1 \mathrm{VAR}=9.96+\mathrm{ISC}=0 \mathrm{NC}=2 \mathrm{TF}=0.610 \mathrm{E}-9$ $\mathrm{TR}=0.610 \mathrm{E}-8 \mathrm{CJE}=0.36 \mathrm{E}-12+\mathrm{VJE}=0.5 \mathrm{MJE}=0.28$ $\mathrm{CJC}=0.328 \mathrm{E}-12 \mathrm{VJC}=0.8 \mathrm{MJC}=0.4+\mathrm{XCJC}=0.074$ $\mathrm{CJS}=1.39 \mathrm{E}-12 \mathrm{VJS}=0.55 \mathrm{MJS}=0.35 \mathrm{FC}=0.5$

.MODEL NX1 NPN RB $=524.6 \mathrm{IRB}=0 \mathrm{RBM}=25 \mathrm{RC}=50$ $+\mathrm{RE}=1 \mathrm{IS}=121 \mathrm{E}-18 \mathrm{EG}=1.206 \mathrm{XTI}=2 \mathrm{XTB}=1.538$. $+\mathrm{BF}=137.5 \mathrm{IKF}=6.974 \mathrm{E}-3 \mathrm{NF}=1 \mathrm{VAF}=159.4$ $\mathrm{ISE}=36 \mathrm{E}-16+\mathrm{NE}=1.713 \mathrm{BR}=0.7258 \mathrm{IKR}=2.198 \mathrm{E}-3$ $\mathrm{NR}=1 \mathrm{VAR}=10.73+\mathrm{ISC}=0 \mathrm{NC}=2 \mathrm{TF}=0.425 \mathrm{E}-9$ $\mathrm{TR}=0.425 \mathrm{E}-8 \mathrm{CJE}=0.214 \mathrm{E}-12+\mathrm{VJE}=0.5 \mathrm{MJE}=0.28$ $\mathrm{CJC}=0.983 \mathrm{E}-13 \mathrm{VJC}=0.5 \mathrm{MJC}=0.3+\mathrm{XCJC}=0.034$ $\mathrm{CJS}=0.913 \mathrm{E}-12 \mathrm{VJS}=0.64 \mathrm{MJS}=0.4 \mathrm{FC}=0.5$.

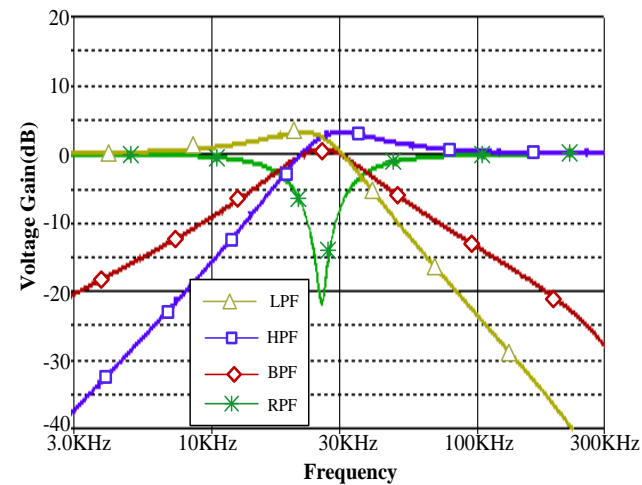

Fig. 4. Gain responses of the proposed circuit working as universal filter.

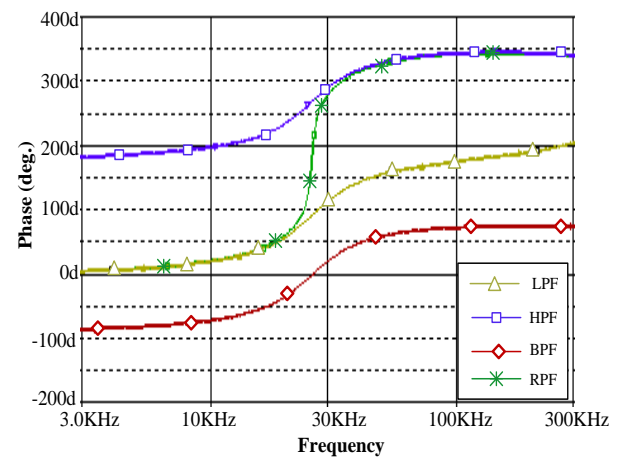

Fig. 5. Phase response of OTA-URC circuit propose universal biquad filter

Fig.6 shows the gain response of the band-pass functions responses for different values of bias current where $I_{B}$ is set $100 \mu \mathrm{A}, 150 \mu \mathrm{A}$ and $200 \mu \mathrm{A}$ respectively. This shows that the pole frequency can be adjusted without affecting the quality factor.

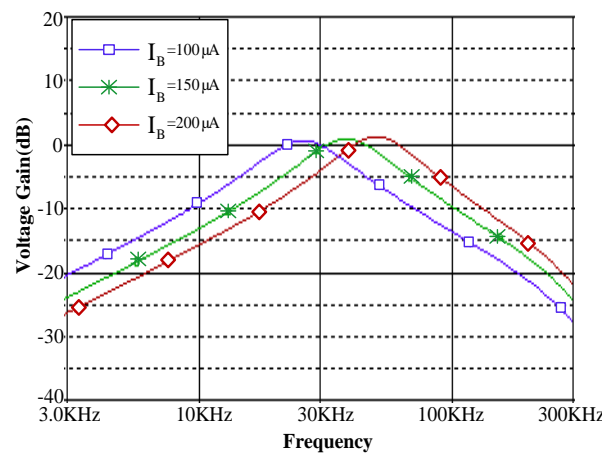

Fig. 6. Band-Pass frequency responses for different values of bias current.

\section{Circuit Sensitivity}

Based on the sensitivities expression $S_{x}^{y}=(x / y) \times(\partial y / \partial x)$, via Eq. (3), the sensitivities of the proposed circuit can be found as

$$
\begin{gathered}
S_{C_{1}}^{\omega}=S_{g_{m 2}}^{\omega}=\frac{1}{2} \\
S_{C_{2}}^{\omega}=S_{R_{1}}^{\omega}=S_{R_{2}}^{\omega}=S_{g_{m 1}}^{\omega}=-\frac{1}{2} \\
S_{C_{1}}^{Q}=S_{R_{1}}^{Q}=S_{g_{m 2}}^{Q}=-\frac{1}{2} \\
S_{C_{2}}^{Q}=S_{R_{2}}^{Q}=S_{g_{m 1}}^{Q}=\frac{1}{2}
\end{gathered}
$$

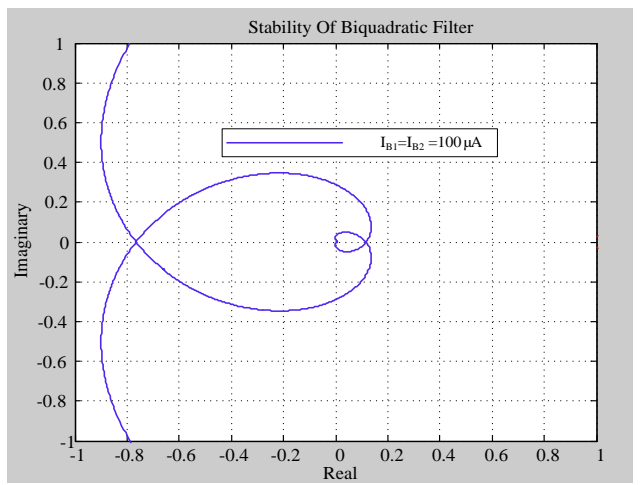

Fig. 7. Stabilities of the biquad filter.

\section{Circuit Stabilities}

The stability of the circuit can be obtained from denominator of Eq. (3). For stability consideration the Nyquist theory contour is encircled at original as show in Fig. 7 and Fig. 8 shows the simulated biquad filter stabilities when various the $\mathrm{DC}$ bias current $\left(\mathrm{I}_{\mathrm{B} 1}\right.$ and $\left.\mathrm{I}_{\mathrm{B} 2}\right)$. The simulation results of circuit indicate is contour is encircled at original point. That means the biquad filter circuit is stable.

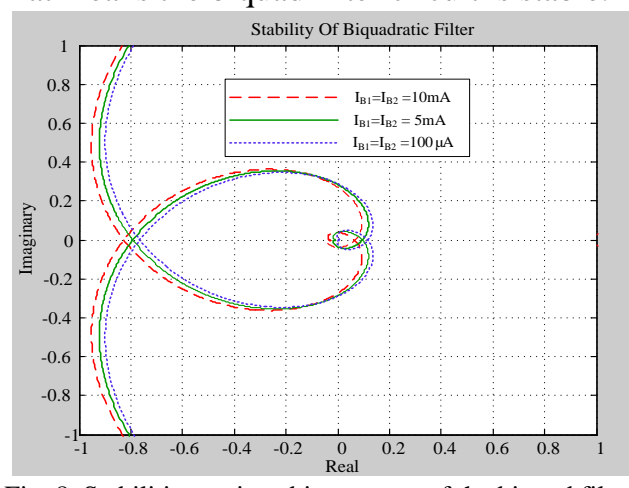

Fig. 8. Stabilities various bias current of the biquad filter.

\section{CONCLUSIONS}

We have proposed the OTA-URC circuit universal biquad filter. The proposed biquad can realize voltage-mode universal filtering responses (low-pass, high-pass, band-pass and band-reject) form the same topology. Filters using the simpler structure have the advantages of lower cost, chip area, power dissipation and noise. The circuit enjoys the advantage of high input impedance, amplitude responses for universal biquadratic filter. The cut off frequency $\left(\omega_{P}\right)$ and quality factor $(Q p)$ are independently controlled. The simulation 
results are in reasonably good agreement with the theoretical. The proposed circuit can be suitable for fabrication by LSI process. It will be useful for universal biquad filter circuit.

\section{REFERENCES}

[1] J. W. Horng, "Voltage-mode universal biquadratic filter using two OTAs and two capacitors," IEICE 2003, E86-A, pp.411-413, 2003.

[2] J. Wu, "Current-mode high-order OTA-C filters," Int J Electron 1994, vol. 76, pp.1115-1120, 1994

[3] C. M. Chang and P. C. Chen, "Universal active filter with current gainusing OTAs," Int J Electron 1991, vol. 71, pp. 805-808, 1991.

[4] J. W. Horng, "Voltage-mode universal biquadratic filter with one input and five outputs using OTAs," Int J Electron 2002, vol. 89, pp.729-737, 2002.

[5] Y. Sun, "Second-order OTA-C filters derived from Nawrocki-Klein biquad," Electron Lett 1998, vol. 34, pp. 1449-1150, 1998.

[6] C. M. Chang and S. K. Pai, "Universal Current-Mode OTA-C Biquad with minimum components," IEEE Trans Circuits Syst I: Fundam Theor Appl 2000, vol.47, pp.1235-1238, 2000.

[7] C. M. Chang, "New multifunction OTA-C Biquads," IEEE Trans Circuits Syst II: Analog Digit Signal Process 1999, vol. 46, pp. 820-824, 1999.

[8] V. Pirajnanchai, S. Luangphakorn, J. Nakasuwan, and K. Janchitrapongvej, "Novel Technique using Pole Amplifier in Sinewave Oscillator," in ISCCSP, 2004.

[9] A. S. Sedra and K. Smith, "Microelectronic Circuit Sedra/Smith," Oxford University Press.

[10] M. S. Ghausi and T. J. Kelly, "Introduction to Distributed Parameter Network with Application to Integrated Circuits," H. R. Andwinston, INC, pp.271.

[11] D. R. Frey, "Log-domain filtering: an approach to current-mode filtering," IEE Proceeding of Circuit Devices Systems, vol. 140, pp. 406-416, 1993.

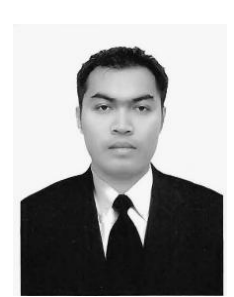

Supachai Klungtong received the B.Sc. degree in Telecommunication Engineering from King Mongkut's Institute of Technology Ladkrabang (KMITL) and M.Eng. degrees in Electrical Engineering from Rajamangala University of Technology Thanyaburi (RMUTT), Thailand, in 2002 and 2011, respectively. In 2012, He is currently in a Doctoral program in electrical engineering at King Mongkut's Institute of Technology Ladkrabang (KMITL), Thailand. In 2005, he worked in Business Development Department at SAMART PCL. His research interests are mainly in high frequency circuits design, analog and digital signal processing, active filter design and power energy saving.

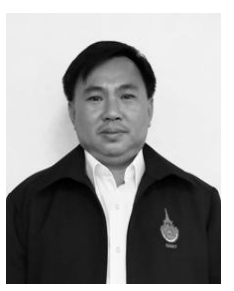

Virote Pirajnanchai was born in Bangkok, Thailand in 1969. He received the B.Eng. in Electronic Engineering from Rajamangala Institute of Technology (RIT), Bangkok, Thailand in 1991, M.Eng in Electrical Engineering from King Mongkut's Institute of Technology Ladkrabang (KMITL), Bangkok, Thailand in 2004. He is currently in a Doctoral program in electrical engineering at the same institute. Currently, he is a Instructor in Electronic and Telecommunication Department at Rajamangala University of Technology Thanyaburi. His research interests are mainly in high frequency circuits design, analog and digital signal processing and active filter design

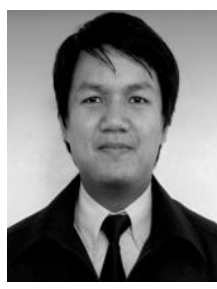

Paitoon Rakluea received the B.Ind.Tech. (2nd Class Honors), M.Eng. in Electrical Engineering and D.Eng. degrees in Electrical Engineering from King Mongkut's Institute of Technology Ladkrabang (KMITL), Thailand, in 2000, 2003 and 2010, respectively. In 2003, he joined the Department of Electronic and Telecommunication Engineering, Rajamangala University of Technology Thanyaburi (RMUTT), Thailand, as an instructor. His current research interests include printed antennas design for wireless communication systems, antenna measurement systems, and wireless networks.

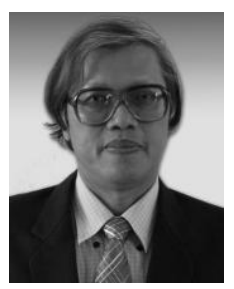

Kanok Janchitrapongvej received the B.Eng in telecommunication engineering from King Mongkut's Institute of Technology Ladkrabang (KMITL), Bangkok, Thailand. He obtained his M.Eng. and D.Eng. from Tokai University, Japan, in 1977 and 1986, respectively. He has been with the Department of Information Engineering since 1977. He is currently an associate professor with KMITL. From 2006 to 2008 , he was the director of the research center for communication technology at KMITL. His research interests include audio and video equalizers, filter design, and the general area of signal processing. 